\title{
Depressão e Antidepressivos: temas geradores para discussão de conceitos químicos no nível médio de ensino
}

\author{
Danielle Silva Lima \\ Kathynne Carvalho Freitas \\ Ricardo Alexandre Figueiredo Matos \\ Márlon Herbert Flora Barbosa Soares \\ Wesley Fernandes Vaz
}

\begin{abstract}
Resumo
Esse trabalho tem a proposta inicial de inserir a contextualização no ensino de Química, como uma forma de favorecer o processo de ensino aprendizagem por meio de um tema gerador. Nesse enfoque o tema escolhido foi a "Depressão", de linguagem bem atual e relevante na sociedade. A ideia é explorar conceitos relacionados à massa atômica, molecular, além de fórmulas moleculares e estruturais. A coleta de dados foi obtida por meio de vídeo, questionário e da observação participante registrada em diário de campo, optouse pela utilização de uma abordagem qualitativa descritiva para entender e discutir os dados obtidos. Os resultados mostraram que os alunos desenvolveram uma melhor compreensão de conceitos como estrutura molecular, determinação de massa molecular, formação de íons em compostos e a associação destes conceitos e da química de uma forma geral com áreas como saúde, farmacologia e questões sociais.
\end{abstract}

Palavras-chave: contextualização; tema gerador; depressão.

\section{Abstract}

Anti Depressive, Neurotransmitters and Depression: generating themes

\section{for discussion of chemical concepts in high school.}

This work has the original proposal to include the contextualization and teaching chemistry, as a way of facilitating the process of learning by teaching through a theme. In this approach the theme chosen was "Depression", by language very current and relevant in society. The idea is to explore concepts related the mass number, mass molecular and molecular and structural formulas. Data collection was obtained through video, questionnaires and participant observation recorded in fieldwork, opted for the use of qualitative descriptive approach to understand and discuss the data. The results showed that the students developed a better understanding of concepts such, molecular weight determination, formation of ions in compounds and their association with concepts and chemistry of a generally with areas like health, pharmacology and social issues.

Key words: contextualization, theme generator; depression. 


\section{Introdução}

A escola tem um papel fundamental na educação no sentido de desenvolver competências básicas integradas com os saberes disciplinares, que facilitem ao seu público o exercício pleno da cidadania e possibilitem assegurar que todos os indivíduos possam ter acesso a uma forma de desenvolver e ampliar suas capacidades como forma de se combater a exclusão social. Na área de Química, particularmente, isso pode se tornar possível caso ocorra uma mudança de postura do professor em relação à forma de tratar o conteúdo de química e ciências, possibilitando uma nova prática pedagógica.

Com o objetivo de formar um ser crítico e social, os Parâmetros Curriculares Nacionais (PCN) (BRASIL, 1999) e mais recentemente as Orientações Curriculares Nacionais (OCN) (BRASIL, 2006) propõem/sugerem um ensino de Química centrado na interface entre informação científica e contexto social. Isto implica um ensino contextualizado, com o objetivo de relacionar os conteúdos de Química com o cotidiano dos alunos, respeitando-se o meio onde estão inseridos, visando à formação do cidadão, o que faz de sua participação na sociedade mais efetiva, trazendo, com isso, uma maior relevância do ensino de Química à vida das pessoas.

Segundo Demo (1999), a contextualização significa a vinculação do ensino com a vida do aluno, bem como com as suas potencialidades. Portanto, o ensino de Química descontextualizado, que preza meramente a transmissão de conteúdo científico pronto e acabado, tende a fazer o aluno memorizar sem que, na maioria das vezes, este compreenda o conceito. Temas que contextualizam o ensino de Química são sugeridos como boa possibilidade de dar sentido aos conceitos científicos.

No entanto, cabe destacar que, segundo Lopes (2002),

O conceito de contextualização foi desenvolvido pelo MEC por apropriação de múltiplos discursos curriculares, nacionais e internacionais, oriundos de contextos acadêmicos, oficiais e das agências multilaterais. Analiso especialmente a apropriação de discursos acadêmicos, mas é preciso considerar que essa apropriação tanto pode ter sido realizada por influência direta dos textos acadêmicos sobre os elaboradores dos parâmetros, quanto por intermédio de uma mediação realizada em reformas educacionais de outros países que influenciaram a reforma brasileira e/ou pelas agências financiadoras multilaterais (p. 390).

A autora ainda discute que o conceito de contextualização acaba por ter um caráter híbrido, no qual, ao mesmo tempo em que prega uma aproximação com valores do cotidiano do cidadão e de um discurso aparentemente acadêmico, é permeado por estratégias eficienticistas de manutenção do capital e do incentivo a produção e ao mercado. 
A inclusão de temas sociais no currículo promove a compreensão, pelos alunos, de processos químicos e de consequências da aplicação da Química na realidade social. Para Zanon (2008, p. 240),

\begin{abstract}
"Falar numa educação básica com valores para uma cidadania emancipatória, democrática, ética e socialmente responsável implica falar num ECN (Ensino de Ciências Naturais) não propedêutico, capaz de promover aprendizados direcionados para a melhora da vida fora da escola, não pela mudança conceitual por via da substituição de conhecimentos cotidianos por científicos, nem pela consideração do estudante como 'tábula rasa' ou da ciência como dogma/verdade, mas pela via do desenvolvimento de uma mente humana constituída por uma pluralidade de conhecimentos dinamicamente contextualizados e inter-relacionados".
\end{abstract}

A presença da química no dia-a-dia das pessoas é mais do que o suficiente para justificar a necessidade do cidadão ser informado sobre esta. Todavia, o ensino atual de nossas escolas está muito distante do que o cidadão necessita conhecer para exercer a sua cidadania (SANTOS e SCHNETZLER, 2003).

Para o ensino de Química voltado para a cidadania, é necessário que existam certas mudanças. Nesse intuito, é importante que o jovem reconheça o valor da ciência, e através dela busquem informações para si e os conteúdos a serem ensinados devem ter uma estreita relação com aspectos da vida do aluno. O OCN (BRASIL, 2006, p. 109) ressalta essa tendência:

"O ensino de Química tem que possibilitar ao aluno a compreensão tanto dos processos químicos em si, quanto da construção de um conhecimento cientifico em estreita relação com as aplicações tecnológicas e suas implicações sociais, políticas e econômicas".

Considerando que a contextualização deve considerar aspectos relevantes e do dia a dia da vida das pessoas como modo de situá-las frente a maneiras de lidar com os problemas sociais que estão presentes na sociedade, um tema que pode ser considerado recorrente atualmente na sociedade em que vivemos é a "Depressão". Tanto em discussões familiares, como na escola, os adolescentes acabam por incluir em suas conversas, uma série de aspectos relacionados a essa doença, no entanto, em um prisma social, desvinculado dos aspectos científicos, fator que pode auxiliá-lo no entendimento do termo, da doença e de como ela vem se inserindo em nossa sociedade.

Apesar dessa visão, descrita resumidamente no parágrafo anterior, ainda localizar-se no nível do senso comum, um estudo de Bromet et. al. (2013) em 18 países, incluindo a Europa, Ásia e América do sul, mostra que a depressão é a doença que mais cresceu nos últimos anos e será uma das principais doenças do mundo quando estivermos próximos a 2020, o que preocupa 
grandemente a Organização Mundial de Saúde por tratar-se de um distúrbio relacionado à saúde mental dos indivíduos. Tais aspectos já parecem ser uma realidade no dia a dia de vários indivíduos.

A partir dessa ideia, tanto discussões conceituais, quanto socioeconômicas podem ser discutidas. Assim, faz-se necessário uma pequena discussão sobre o tema.

\section{A Depressão como Tema Gerador}

A Depressão é uma doença psiquiátrica que atinge de $3 \%$ a $5 \%$ da população mundial. Para Kaplan e Sadock (1993) o risco de depressão ao longo da vida é de 3 a 12\% para os homens e 20 a $26 \%$ para as mulheres. A prevalência de transtornos afetivos em adolescentes é de aproximadamente $5 \%$ e, as mulheres são, em média, duas vezes mais afetadas que os homens, a partir da adolescência. Ela é caracterizada por oscilações abruptas de humor, com episódios de depressão e de mania (o oposto da depressão). Suas causas são diversas, sendo algumas biológicas, porém a maior parte dessas causas vem de pressões ambientais e, com o aumento do estresse das pessoas em seu dia-a-dia, principalmente nas grandes cidades, não é surpreendente que este número esteja aumentando.

Várias teorias foram propostas para explicar as causas bioquímicas relacionadas à depressão. Em sua maioria atribuem papel fundamental a alguns neurotransmissores, tais como dopamina, norepinefrina e serotonina. Assim, segundo uma hipótese bastante recorrente na literatura, os distúrbios afetivos ligados a depressão resultam das deficiências genéticas na atividade funcional destes neurotransmissores (KOROLKOVAS, 2005).

Para tentar combater tais deficiências, principalmente aquelas relacionadas a distúrbios afetivos, são propostas alternativas de tratamentos por meio de antidepressivos. Os fármacos antidepressivos são aqueles usados para restaurar pacientes mentalmente deprimidos a um estado mental melhorado, reduzindo a intensidade dos sintomas. Desta forma, reduzem a tendência ao suicídio e aceleram a velocidade de normalização do sujeito.

A demora do início de atividade clínica destes fármacos levou à hipótese atual de que os efeitos farmacológicos e clínicos produzidos pela administração destes agentes por tempo prolongado resultam de alteração gradual, ou mudanças "adaptativas", de receptores adrenérgicos, dopaminérgicos e serotoninérgicos centrais selecionados, tais como diminuição do número destes auto-receptores, em conseqüência perda de sensibilidade causada pela maioria dos antidepressivos.

Tais alterações e características conduzem a um aumento nos níveis de alguns neurotransmissores no sistema nervoso central e, portanto, à reversão de uma parte dos 
sintomas ligados a depressão. Contudo, alguns antidepressivos, como a mianserina, não produzem a perda de sensibilidade (KOROLKOVAS, 2005).

Os antidepressivos, em sua maioria, elevam primariamente os níveis da norepinefrina ou da serotonina, ou de ambas, no sistema nervoso central, inibindo a recaptação destas nas terminações nervosas. Alguns poucos antidepressivos também bloqueiam a recaptação da dopamina. Os inibidores da Monoamina Oxidase (MAO) aumentam estes níveis impedindo a oxidação destas aminas. Alterações adaptativas de receptores da histamina e opiáceos também desempenham papel no mecanismo de ação dos antidepressivos (KOROLKOVAS, 2005).

Quando o tratamento é ambulatorial procura-se sempre utilizar-se da menor dose, que é gradualmente aumentada, se necessário. Nos pacientes hospitalizados pode-se empregar uma dose maior, e o tempo para atingir a máxima é usualmente mais curto. Quando a fase inicial termina, é recomendável que o tratamento seja prolongado por mais seis meses. Neste período geralmente reduz-se a dose para diminuir os efeitos adversos. Para evitar a síndrome de abstinência, a interrupção do tratamento deve ser gradual (MATOS e SOUZA, 1999).

Depois de 50 anos de sua introdução na prática psiquiátrica, outra classe de antidepressivos, os sais de lítio permanecem como o tratamento de escolha para a maioria dos casos de mania aguda e para a profilaxia das recorrências das fases maníaco-depressivas. Na mania aguda, a eficácia do lítio situa-se, conforme o tipo de pacientes incluídos, entre $49 \%$ (estudo de apenas três semanas, incluindo casos anteriormente resistentes) e $80 \%$ dos casos, mostrando-se mais específico do que outros medicamentos na redução dos sintomas nucleares da mania (exaltação do humor, aceleração do pensamento e idéias de grandiosidade); em contraposição, alguns antidepressivos mostram-se mais rápidos e eficazes no controle da hiperatividade e da agitação psicomotora, sugerindo que sua ação se devesse a uma sedação mais inespecífica. Numerosos estudos controlados confirmam a eficácia do lítio na profilaxia de ambas as fases (maníacas e depressivas) do transtorno bipolar (DEL PORTO, 2004).

Os antidepressivos são bem absorvidos quando administrados por via oral, extensivamente biotransformados, altamente ligados a proteínas plasmáticas e teciduais e lentamente eliminados. Dentre os antidepressivos mais usados no Brasil estão o Carbonato de Lítio e a Fluoxetina.

Considerando-se esse aspecto, escolhemos esses dois medicamentos para abordar a temática escolhida, já que são os mais utilizados pela sociedade nos tratamentos relacionados à depressão. Logo, faz-se necessário algumas considerações sobre tais compostos, ressaltando suas principais características químicas:

Carbonato de Lítio: Sua fórmula molecular é $\mathrm{Li}_{2} \mathrm{CO}_{3}$. É um pó branco, granular e inodoro, pouco solúvel em água. Deve ser administrado sob cuidadosa vigilância médica. As doses terapêuticas estão muito próximas das doses tóxicas. Seu mecanismo de ação não está 
completamente elucidado. Julga-se, porém, que o efeito estabilizante do humor está relacionado com a redução da concentração do neurotransmissor catecolamínico, provavelmente medida pelo efeito do íon lítio sobre a $\mathrm{Na}^{+} \mathrm{K}^{+}$ATPase para melhorar o transporte do íon sódio através da membrana transneuronal; segundo outra hipótese, o lítio pode diminuir a concentração do ATP cíclico, o que resultaria em sensibilidade diminuída dos receptores da adenilciclase hormôniosensíveis.

Fluoxetina: Conhecido comercialmente como Prozac, pertence à primeira nova classe de drogas relacionadas com a inibição da captação da serotonina pelo sistema nervoso central, a ser aprovada para uso nos Estados Unidos. Ela foi primeiro liberado para o tratamento de depressão na Bélgica em 1986 e nos Estados Unidos em 1987. Desde então, já foi aprovada e comercializada em mais de 90 países e usada por mais de 40 milhões de pessoas no mundo (MILES et al., 2001).

Mais tarde se descobriu que uma dosagem maior de Prozac tinha efeito para pacientes com Bulimia e foi liberada para este uso pelo Food and Drug Administration (FDA) em 1996. Em dois anos, o Prozac atingiu o status de droga mais prescrita e ainda é hoje o antidepressivo mais utilizado mundialmente. É derivada da feniltrifluortoliloxipropilamina e é usada na forma de cloridrato. A utilização deste pode ocorrer efeitos colaterais alérgicos (coceira), neurológicos (dor de cabeça, tremores, tonturas), comportamentais (insônia, ansiedade, nervosismo, agitação, tonturas e fadiga) e respiratórios (bronquite, rinite) (MILES et al., 2001). Sua fórmula estrutural é apresentada na figura 1.

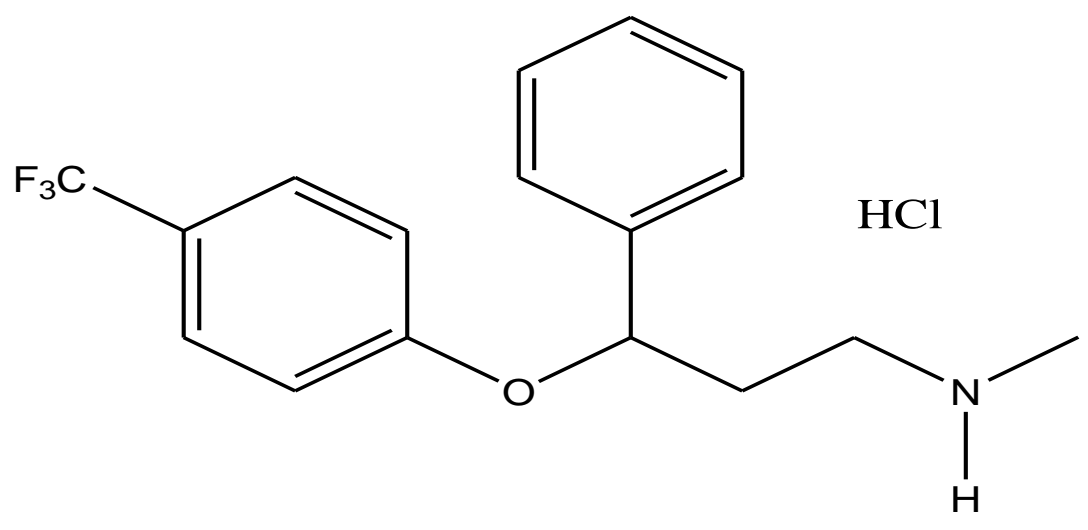

Figura 1 - Fórmula estrutural do PROZAC: Cloreto de 3-(p-trifluorometilfenóxi)-N-metil-3fenilpropilamônio

Portanto, considerando-se essas discussões iniciais, é perceptível que conteúdos químicos diversos podem ser debatidos a partir da exploração dos medicamentos apresentados, seja quimicamente ou em relação a aspectos socioeconômicos envolvendo a comercialização de tais 
drogas bem como o reflexo da doença e de seus remédios na sociedade e logicamente, suas relações diretas e indiretas com o conhecimento químico.

Alguns conceitos a serem explorados a partir do tema são descritos a seguir: propriedades físicas e químicas das substâncias; estrutura molecular; reações químicas; equilíbrio químico; mecanismo de ação e efeitos adversos de fármacos, ligações químicas, entre outros. Seu emprego ainda pode despertar a curiosidade dos alunos ao discutir as questões sociais e psicológicas, que envolvem a depressão. Entre tantos conteúdos apontados, os estudos sobre depressão não envolvem somente a Química, como também a Biologia, Psicologia, entre outras.

Finalmente, o objetivo desse trabalho é possibilitar aos alunos do Ensino Médio a discussão de um tema químico social: Anti Depressivos e Depressão, o que pode vir a desempenhar importante papel na formação de um cidadão crítico.

\section{Procedimento Metodológico}

Dentre os conceitos já descritos anteriormente, possíveis de serem trabalhados em sala de aula e considerando-se o nível de ensino escolhido, os conteúdos que optamos por estudar foram: moléculas, massa atômica, massa molecular, fórmulas moleculares e estruturais.

Uma instituição da rede pública federal foi o ambiente escolhido para realizar este trabalho. Os participantes foram 25 alunos do primeiro ano do Ensino Médio. A atividade teve duração de três horas o que corresponde a duas aulas de 1 hora e 30 minutos em dias diferentes. As aulas foram gravadas em áudio e vídeo para posterior análise. Aplicou-se também um questionário aos alunos além das anotações em diário de campo. A partir dos dados obtidos pelas aulas gravadas e também pelas respostas dos questionários, optou-se por uma abordagem qualitativa descritiva dos resultados.

Para dar início a aula foi enfatizada o tema "Depressão" com o intuito de promover um estudo mais contextualizado, interdisciplinar, dinâmico e informativo. Para despertar o interesse dos alunos sobre o tema "depressão" e motivar o início da discussão foi exposto um vídeo "Como funciona a depressão", retirado do site de compartilhamento de vídeos conhecido como YOUTUBE (http://www.youtube.com/watch?v=LEup7sbCxPI). O vídeo informativo com duração de 3 min50s apresenta alguns dados sobre a doença, como por exemplo: os sintomas, as causas, os efeitos colaterais, o crescente número de pessoas afetadas, as principais vítimas e as forma de tratamento. Com base no vídeo, iniciou-se um debate com a participação dos alunos com o objetivo de compartilhar ideias e dúvidas sobre a doença.

É importante ressaltar, que todo o conteúdo abordado enfatizou os fármacos antidepressivos escolhidos para o trabalho, o Carbonato de Lítio $\left(\mathrm{Li}_{2} \mathrm{CO}_{3}\right)$ e a Fluoxetina $\left(\mathrm{C}_{17} \mathrm{H}_{18} \mathrm{NF}_{3} \mathrm{O}\right)$ conhecida comercialmente como Prozac. 
Estes dois fármacos tiveram suas características exploradas, como por exemplo: seus efeitos colaterais, as propriedades gerais dos compostos, e as fórmulas moleculares e estruturais. As fórmulas moleculares e estruturais dos fármacos foram trabalhadas de forma simples, utilizando o modelo molecular atômico e a visualização das imagens em três dimensões (3D),

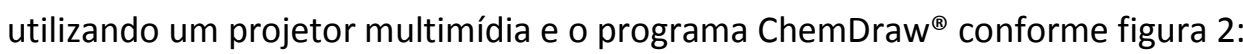

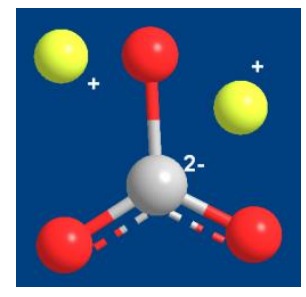

(A) Modelo molecular do Carbonato de Lítio

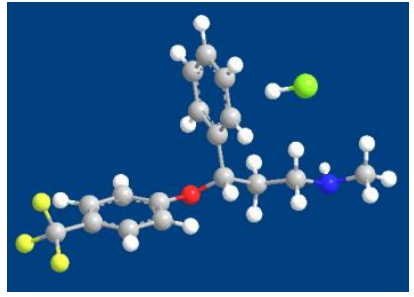

(B) Modelo molecular da Fluoxetina

Figura 2 - Modelos Moleculares para o Carbonado de Lítio (A) e a Fluoxetina (B).

Ao final da aula ministrada, foi aplicado o questionário com três perguntas sobre o tema abordado, para levantar algumas concepções dos estudantes. 0 principal objetivo era perceber 0 que os alunos conseguiram perceber dos conceitos e da temática, como um todo. O questionário foi respondido de forma individual, e assim foi possível verificar houve algum tipo de melhoria em termos de aprendizagem quando comparado a ações anteriores do professor da disciplina e também dos pesquisadores envolvidos.

\section{Resultados na Sala de Aula - As Vozes dos Alunos}

Ao propor a realização da atividade por meio do tema "Depressão", a aula foi iniciada com algumas perguntas direcionadas aos alunos, com a intenção de se obter o conhecimento prévio do aluno. É evidente que, para o cidadão efetivar a sua participação na sociedade, é necessário que ele disponha de informação. Para Santos e Schnetzler (2003, p. 47), "Tais informações são aquelas que estão diretamente vinculadas aos problemas sociais que afetam o cidadão, os quais exigem um posicionamento quanto ao encaminhamento de suas soluções".

Com base na participação dos alunos ao responderem perguntas feitas pela professora, como por exemplo: "Para vocês o que vem a ser depressão?", verificou-se que os alunos estavam bem tranquilos e desinibidos ao responderem e darem suas opiniões. Por isso, foram obtidas várias respostas, como algumas selecionadas a seguir:

"Depressão é o isolamento de uma pessoa".

"Depressão é uma doença e tem tratamento". 
"Depressão é estar triste sem motivo ou até mesmo angustiado".

Podemos notar que as respostas dos alunos, parecem se aproximar mais dos sintomas originados por tal doença do que de uma definição propriamente dita. Apesar de reconhecê-la como uma doença, não há uma relação imediata com o fato de ela ser ou não psiquiátrica. Os sintomas mais comuns foram citados pela maioria dos alunos, como a procura pelo isolamento e uma tristeza ou angústia sem motivos aparentes. Assim, o tema gerador funcionou para explicitar o que os alunos entendiam como depressão. Nesse aspecto, eles a entendem como sintomas clássicos observados em seu dia a dia.

Se fôssemos classificar as respostas obtidas em um nível de acerto ou aproximação com alguma definição, poderíamos dizer que elas são parcialmente satisfatórias. Se não definem propriamente, descrevem adequadamente seus sintomas.

Como o tema é atual e relevante, alguns alunos se mostraram entusiasmados e interessados, por isso alguns até chegaram a contar fatos que ocorreram em suas vidas:

“Eu tenho caso de 'depressão' na minha família, meu pai e minha irmã são depressivos".

"Eu tenho depressão, porém está controlada, porque faço tratamento, tomo remédio há algum tempo e não posso parar de tomá-los, pois meu médico disse que posso voltar a ficar depressiva".

Tal conhecimento de causa por parte dos alunos mostra a importância da temática em sala de aula. As duas frases selecionadas procuram mostrar que a maior parte dos alunos participantes convive frequentemente com o tema em suas vidas. Segundo Saint Clair (2009), a depressão é um dos temas mais trabalhados na mídia, seja televisiva ou digital. Tal fator tem relação com a relevância do tema e com o fato de se usar medicamentos para diminuir sintomas que podem ter causas psicológicas estritamente relacionadas com a sociedade em que vivemos, mas que também podem ter causas físicas, ligadas a distúrbios químicos ou neuroquímicos.

Dando continuidade a atividade, aplicou-se um vídeo, com o nome "Como funciona a Depressão", e nele foi possível informar aos alunos dados sobre a doença, esclarecendo as dúvidas, seus efeitos colaterais, seu tratamento, o número de pessoas afetadas e as principais vítimas. Durante a apresentação do vídeo, observou-se que os alunos comentavam entre si, faziam "piadinhas" com determinados colegas dizendo "Você vive fazendo drama, então você é uma pessoa depressiva", e alguns se mostraram espantados com tantas informações, concluindo desta forma que, em relação à doença, apesar de parecerem informados, desconheciam uma série de fatos e fatores. 
Com a finalização do vídeo, notou-se que os alunos estavam mais envolvidos na atividade, a partir deste ponto, foi iniciado um debate envolvendo os alunos. No debate, algumas perguntas foram realizadas por parte dos estudantes como:

"Professora, podemos dizer que a depressão é uma doença hereditária?".

"Por que a depressão afeta mais as mulheres?".

"A depressão tem tratamento, mas será que um dia ela é totalmente curada?".

A professora procurou responder da melhor forma possível, todas as perguntas, apesar de não ser uma profissional da área, para finalmente, tentar direcionar a discussão para o foco da aula, em relação às estruturas escolhidas.

O próximo passo foi começar a discussão a respeito dos medicamentos. Apresentaram-se aos alunos os dois compostos escolhidos por meio de modelos tridimensionais, conforme Figura 2. A partir daí, começou-se a explicar aos alunos que os compostos ali apresentados eram modelos que simulavam macroscopicamente os medicamentos apresentados, mais utilizados no tratamento da depressão.

Com essa deixa, e a partir das perguntas dos alunos sobre modelos representativos, começou-se a discussão sobre modelos atômicos e que tipo de modelo atômico explicaria aquelas estruturas. Em relação aos modelos apresentados e após a explicação, algumas frases puderam ser colhidas:

"Professora que estrutura mais doida".

"Nossa que fera, mas eu acho meio difícil de entender esses compostos moleculares."

"Essas bolinhas coloridas representam os átomos?".

Observa-se que os alunos já começam, mesmo que superficialmente, a fazer uma relação entre modelo e representação, sabendo-se não se tratar efetivamente do composto ou da estrutura real, mas uma representação desta. Apresentando um medicamento antidepressivo ao mesmo tempo em que se fala sobre modelos em química, podemos tentar aproximar o que é observável, isto é, o princípio ativo aglomerado em cápsulas ou comprimidos, do que pode ser explicada por meio de modelos teóricos, no caso, a apresentação pictórica do mesmo princípio no quadro ou na projeção, fazendo com que o aluno enxergue que aquela representação não está tão distante da sua manipulação concreta. Assim, segundo Rosa e Schnetzler (1998), melhora-se a compreensão do aluno sobre o papel dos modelos teóricos na interpretação de fenômenos e a na construção de conceitos fundamentais do conhecimento químico, como por exemplo, o de substância. 
A partir dos dois fármacos apresentados foram explorados alguns conceitos químicos, como por exemplo: números atômicos, massa atômica, massa molecular, e as fórmulas moleculares e estruturais. Utilizando-se das estruturas, a professora discorreu sobre a massa molar de uma substância. Suas definições e conceitos, bem como massa atômica e número atômico, fazendo a devida relação com a tabela periódica.

Perguntas dos alunos giravam em torno de "por que a massa molecular do prozac era maior do que o composto de lítio se os efeitos eram semelhantes?"; "os tamanhos diferentes dos átomos que constituem a molécula tem relação com o efeito do remédio?", entre outras. Salientase que na aula anterior, os alunos haviam tido contato com o conceito de átomo, molécula e número atômico.

Outro aspecto interessante foi a colocação por parte dos alunos, sobre qual a quantidade de moléculas de cada um dos medicamentos apresentados estaria presente em cada cápsula ou comprimido do medicamento. Comparando-se os dois modelos apresentados, alguns alunos inferiram que a quantidade de carbonato de lítio em um medicamento é maior do que a do Prozac, em comprimidos ou cápsulas do mesmo tamanho. O professor aproveitou a deixa para discorrer sobre a padronização das cápsulas pela indústria farmacêutica, bem como a forma pela qual os medicamentos são vendidos, isto é, sempre em relação à quantidade em $\mathrm{mg}$ do princípio ativo.

Assim, a professora solicitou que alguns alunos fossem até o quadro e calculassem a massa molecular de outras moléculas e até de outros antidepressivos, além é claro, do Carbonato de lítio e da Fluoxetina. Nesse momento, observou-se que os alunos pareciam ficar focados na aula, pois todos queriam ajudar e verificar se o colega conseguiria resolver o exercício. A resolução do exercício por parte dos alunos foi um fator importante para averiguar a viabilidade das aulas, pois os mesmos responderam as questões com facilidade.

Tentando voltar a questões contextuais, perguntamos aos alunos se eles sabiam quais eram os efeitos colaterais desses fármacos, e apenas dois alunos conseguiram responder corretamente, os restantes ficaram calados:

"Como eu tenho depressão, eu tomo a fluoxetina que muitas vezes me causa insônia."

"Eu tenho uma amiga que usa a fluoxetina para poder emagrecer, porque inibe a fome, e como ela se acha gordinha ela utiliza esse remédio, mas ela não tem depressão".

Esse contexto específico em relação aos adolescentes e a depressão é descrito por Baptista et al. (2001). Segundo o autor, é crescente o aumento de doenças relacionados a depressão em adolescentes a partir da década de 80. Dentre os fatores, os principais são os 
problemas relacionados à idade, como os sexuais, os amigos, os pais, não se descartando problemas antes da década de 70 nem os distúrbios eminentemente físicos.

Tal fator é um alerta ao professor em sala de aula. Saber lidar com tais problemas é um saber experiencial necessário em sala de aula e o conhecimento químico pode se mostrar um fator de discussão social interessante e muito válido para um público com pouco acesso a informação de qualidade.

\section{Respostas ao Questionário}

Para finalizar o trabalho, foi entregue aos 25 alunos presentes, um questionário com três questões que abordava algumas discussões ocorridas em sala de aula. A avaliação foi realizada de forma individual, com o intuito de analisar tanto o nível de aprendizagem quanto o interesse dos alunos.

Analisando a primeira questão: (1) "Por meio do exemplo realizado em sala de aula da estrutura molecular da fluoxetina e do carbonato de lítio, vocês serão capazes de encontrar a massa molecular de qualquer outro composto?" Através das respostas encontradas pôde-se dizer que as maiorias dos alunos compreenderam o foco da aula. A figura 3 informa a porcentagem exata:

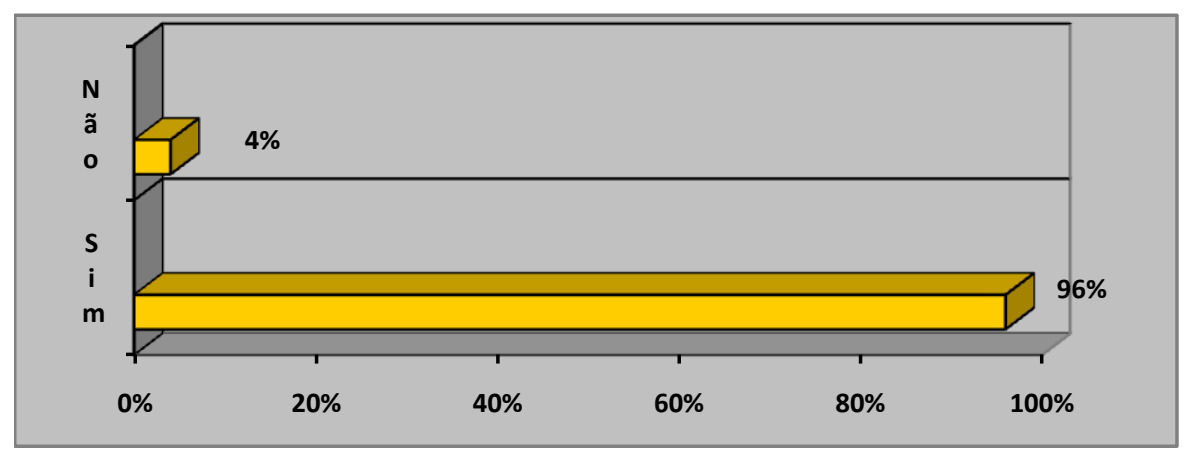

Figura 3 - Respostas para a questão 1.

A seguir estão algumas justificativas dos alunos para a questão 1:

"Professora eu acho mais fácil contar a quantidade de átomos da estrutura em três dimensões pra eu obter a massa molecular, através da quantidade exata de cada elemento e suas respectivas massas".

"Professora se puder olhar a tabela periódica na prova, eu consigo achar o número de massa de qualquer elemento, e conseqüentemente eu descubro a massa molecular do composto."

"Através da massa de prótons e nêutrons eu encontro a massa do elemento".

R. B. E. C. T., vol 6, núm. 3, set-dez.2013 ISSN - 1982-873X 
As respostas sintetizam o entendimento dos alunos sobre a proposta inicial da aula em relação ao ensino de massa molecular ou atômica, apesar de que em alguns casos, notamos uma confusão entre massa molecular e número de massa por parte de uma pequena quantidade das respostas, como descrito anteriormente. Uma grande parte das respostas foi considerada satisfatória em relação à discussão dos conceitos químicos, mas em uma pequena parte podemos notar certa confusão conceitual, o que as tornam insatisfatórias em termos de ensino e aprendizagem e que, se adequadamente exploradas pelo professor, podem se tornar uma eficiente estratégia de discussão conceitual.

Na segunda questão quando foi pedido: (2) "Faça associações do conteúdo de química apresentado por meio das estruturas químicas dos medicamentos com aspectos gerais relacionados à área da saúde". Esta questão tinha o objetivo de relacionar a questão dos medicamentos, os vídeos apresentados e as discussões contextuais e conceituais em sala de aula com outras áreas de saúde e suas implicações diversas. Os estudantes explicitaram as suas opiniões, resumidas na Figura 4:

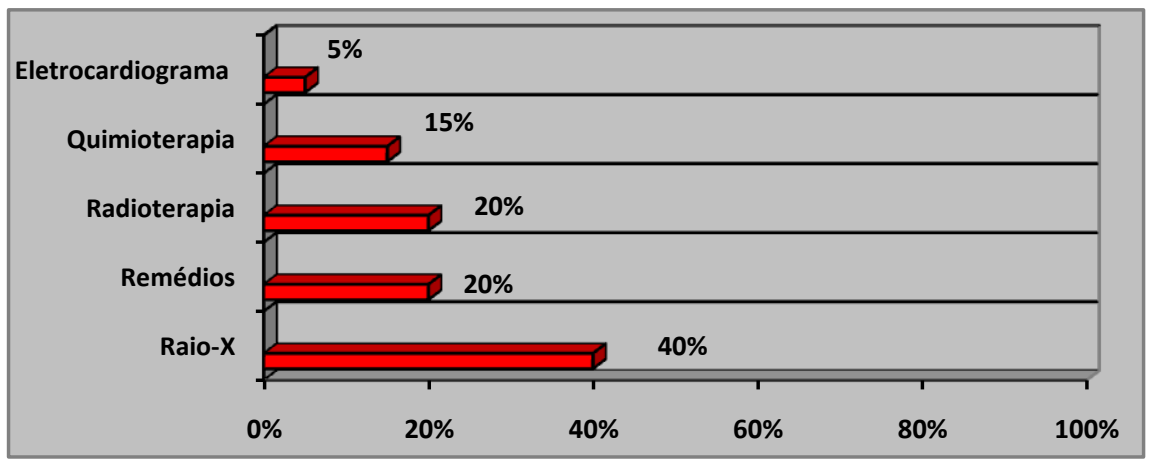

Figura 4-Resposta a questão 2

A seguir estão algumas justificativas dos alunos para a questão 2:

"A química estuda e descobre os mais variados remédios e curas, assim ela pode ajudar na área da saúde prevenindo doenças".

"Através da química, podemos realizar vários exames que facilita na descoberta de doenças, como exemplo, os raios-X."

"Com o avanço da química, a área da saúde melhorou, principalmente no que se refere à quimioterapia."

"A química está presente não só na medicina, mas também na odontologia, pois quando o dentista precisa saber se vai ser necessário fazer o canal no dente, ele usa os raios-X". 
As respostas nos mostram que mesmo após a discussão sobre o uso de medicamentos e as questões econômicas e sociais de sua utilização, os alunos ficaram com uma visão romântica sobre o uso da química na área de saúde. Questões de dependência química, má distribuição de remédios, preços exacerbados de algumas drogas que deveriam ser mais facilmente acessadas pela população não voltaram a aparecer na fala dos alunos como era esperado após a discussão pelo professor. A relação entre química, distribuição e economia não parece ser determinante naquela faixa etária para essa turma, especificamente.

Essa alienação pode ter relação com questões relacionadas à mídia e sua influência na visão da química desse aluno (Mesquita e Soares, 2008) ou ainda, um possível não aprofundamento do próprio professor, desacostumado com o tipo diferenciado de aula, o que pressupõe uma quantidade maior de informação e estudo.

Outro aspecto importante foi a alta presença do raio-x na resposta dos alunos. Isto é, eles creditam tal técnica a um processo químico e não físico. Tal discussão foi realizada pelo professor em sala de aula, no intuito de dirimir dúvidas em relação a isso.

Na terceira questão foi perguntado para os alunos: (3) "Quais os remédios que podem ser utilizados para amenizar a depressão?" A intenção da pergunta, apesar de óbvia, era observar se haveria extrapolação das respostas, ou seja, se haveriam respostas diferentes dos medicamentos trabalhados em sala de aula, com o intuito de aprofundar o conhecimento sobre os conhecimentos prévios dos alunos em relação a esse tipo de medicamento.

Como era de se esperar, a maioria dos alunos respondeu Carbonato de Lítio e Fluoxetina, porém uma porcentagem dos alunos respondeu outros tipos de remédios, como: Valerium, Bup e Luvox. No questionário os alunos justificam as respostas:

"Valerium e Fluoxetina são medicamentos usados para ansiedade, tensão e stress".

"A Fluoxetina é um antidepressivo inibidor da recaptação da serotonina".

"O Carbonato de lítio é um estabilizador de humor".

"O Luvox é um inibidor da recaptação da serotonina que ajuda no tratamento de transtorno obsessivo-compulsivo"

"O Bup é um remédio antidrepressivo, minha mãe fuma e utiliza para controlar a sua ansiedade".

Novamente, as respostas mostram o quanto a depressão parece ser um assunto muito comum aos alunos participantes e em extensão, às suas famílias. As frases selecionadas representam quase que a totalidade das respostas dos alunos, o que de certa forma, é preocupante quando notamos a naturalidade de como se referem a ela, e como ela parece inserida na vida diária dos alunos. Assim, pode-se dizer que a aula realmente conseguiu realizar a 
devida proposta, envolvendo os alunos com o conteúdo químico sem deixar de lado o seu próprio dia a dia. Como afirmam Santos e Schnetzler (2003, p. 90):

"A abordagem do conteúdo requer a sua contextualização social, o que implica a inclusão de temas sociais no programa, relacionados a problemas vinculados a ciência e à tecnologia, a fim de que se possibilite a compreensão do caráter social do ensino e se propicie condições para o desenvolvimento das atitudes relacionadas à cidadania".

É importante salientar que a atividade proporcionou boas relações entre a vivência do estudante e o conceito químico envolvido, no entanto, não podemos afirmar de fato que nossa intervenção teve um caráter amplamente contextual. De fato, podemos comentar quais os níveis de contextualização atingimos nesse trabalho, comentando as expressões comumente utilizadas na literatura como meio de qualificar ou ainda, descrever aspectos relacionados à contextualização, a partir das ideias de Santos e Mortimer (1999), Teixeira (2003), Auler (2003) e Auler e Delizoicov (2006):

1) Contextualização como fatos e ilustrações do cotidiano ou como descrição científica dos fatos e processos: nesse aspecto, por mais que esse tipo de contextualização seja um tanto reducionista, já que trata quase sempre de ilustração do cotidiano, sem necessariamente intervir de fato na vida do aluno, pensamos que foi amplamente satisfatório. Os exemplos discutidos estavam de acordo com o conhecimento do aluno, bem como de se cotidiano, ou seja, houve mais uma descrição científica de fatos relacionados à depressão que se coadunavam com certa realidade do sujeito.

2) Contextualização como um processo de compreensão da realidade social: nesse caso, o princípio que direciona a atividade é o uso do conhecimento químico para o entendimento e possível enfrentamento de situações problemáticas da vida do sujeito, na tentativa de fazê-lo analisar e julgar a situação na qual se encontra utilizando-se da química. Nesse caso, pensamos que atingimos parcialmente tal nível de contextualização. Os alunos conheceram o problema, as formas de combatê-lo bem como as necessidades prementes da depressão na sociedade. Entenderam os aspectos químicos relacionados à medicação de tal enfermidade, mas não conseguiram ir além disso, ou seja, de fazer proposições do uso específico da química para melhoria do problema, a não ser o fato de se medir a quantidade de cada um dos fármacos estudados.

3) Contextualização como transformação da realidade social: nesse caso, um problema social é apresentado bem como as formas de se intervir nessa realizada problematizada. Um aspecto bem difícil de atingir, até mesmo em propostas didáticas problematizadoras. Aqui se propõe estudos e ideias de intervenção que não apareceram no trabalho descrito, como fator de transformação da realidade do aluno envolvido. 
Finalmente, o tema apresentado e discutido com os alunos foi relevante no sentido de motivá-los a uma realidade a qual se inserem em usa vida, além de propiciar aos alunos envolvidos a discussão e o aprendizado de conteúdos específicos por meio de um tema o qual estavam familiarizados, o que é um aspecto importante no início de química e nos aspectos ligados a contextualização.

\section{Considerações Finais}

A temática escolhida, relacionada à depressão atuou de forma estimulante na aprendizagem de conteúdos químicos: evolução dos modelos atômicos, números atômicos, número de massa, massa molecular, e as fórmulas moleculares e estruturais. $\mathrm{O}$ desenvolvimento e as mudanças das ideias dos estudantes durante o processo de ensino foram verificados mediante o acompanhamento das discussões nos debates (registradas em vídeo e áudio), a análise das atividades escritas (questionário), e anotações do diário de campo. Assim, através desta proposta foi possível extrapolar as fronteiras da sala de aula, aumentando o interesse dos alunos por novos conteúdos químicos.

A atividade exigiu uma participação ativa dos estudantes nos processo de aprendizagem, havendo entre os alunos a troca de informação e a renovação de novos conceitos, através de debate e do diálogo. Dessa forma, a abordagem utilizada permitiu valorizar as trocas de ideias entre os parceiros em sala de aula, não deixando de lado seus aspectos de vida. Assim, através de um ensino mais contextualizado acreditamos que o conteúdo químico pode ser melhor trabalhado, sendo uma alternativa para aqueles professores que buscam formar cidadãos mais críticos.

Vale ressaltar que o tema também pode ser utilizado para aplicar outros conteúdos no ensino de Química, como estequiometria, cinética química, reações ácido-base, nomenclatura química orgânica e inorgânica e equilíbrio químico, e outras áreas com, por exemplo, biologia, física, ciências sociais e ciências da saúde.

\section{Referências Bibliográficas}

AULER, D. Alfabetização Cientifico-Tecnológica: um novo “Paradigma”? Ensaio - Pesquisa em Educação em Ciências. Belo Horizonte: v.5, n.1, p. 1-15, 2003.

AULER, D.; DELIZOICOV, D. Ciência-Tecnologia-Sociedade: relações estabelecidas por professores de ciências. Revista Electrónica de Enseñanza de las Ciencias. v.5, n.2, p. 337- 355, 2006.

BAPTISTA, M. N.; BAPTISTA, A. S. D.; DIAS, R. R.. Estrutura e suporte familiar como fatores de risco na depressão de adolescentes. Psicologia: ciência e profissão, v. 21, n. 2, p 52-61, 2001. 
BROMET, E.; ANDRADE, L. H.; HWANG, I.; SAMPSON, N.; ALONSO, J.; GIROLAMO, G.; GRAAF, R.; DEMYTTENAERE, K.; HU, C.; IWATA, N.; KARAM, A.; KAUR, J.; KOSTYUCHENKO, S.; LÉPINE, J. P.; LEVINSON, D.; MATSCHINGER, K.; MORA, M. E. M.; BROWNE, M. O.; POSADA-VILLA, J.; VIANA, M. C.; WILLIAMS, D. R.; KESSLER, R. C.; Cross-national epidemiology of DSM-IV major depressive episode. BMC Biomedicine, v. 9, n. 90, 2011.

BRASIL. Orientações Curriculares Nacionais para o Ensino Médio (OCNEM). Brasília: MEC, 2006. BRASIL. Parâmetros Curriculares Nacionais para o Ensino Médio (PCNEM). Brasília: MEC; 1999. DEL PORTO, J. A. Evolução do conceito e controvérsias atuais sobre o transtorno bipolar do humor. Revista Brasileira de Psiquiatria. v.26, n.3, p. 3-6, 2004.

DEMO, P. A Nova LDB - Ranços e avanços. In: Maria Neusa de Oliveira. (Org.). As Políticas Educacionais no Contexto da Globalização. Ilhéus: Editus (Editora da UESC), v. 1, p. 19-40, 1999. KAPLAN, H. I.; SADOCK, B. J. Compêndio de Psiquiatria. Porto Alegre: Artes Médicas, 1993. KOROLKOVAS, A.. Dicionário Terapêutico Guanabara. São Paulo: Guanabara Koogan S.A., 2005. LOPES, A. R. C.; Os Parâmetros Curriculares Nacionais Para o Ensino Médio e a Submissão ao Mundo Produtivo: o caso do conceito de contextualização. Educ. Soc., v.23, n. 80, p. 386-400, 2002.

MATOS, J. L.; SOUZA, F. G. M. Tratamento da depressão. Revista Brasileira de Psiquiatria, v.21, p. 18-23, 1999.

MESQUITA, N. A. S.; SOARES, M. H. F. B.; Visões de Ciências de Professores de Química: a mídia e as reflexões no ambiente escolar no nível médio de ensino. Química Nova, v. 32, n. 7, p. 18751880, 2008.

MILES, W. H.; FIALCOWITZ, E. J.; SCOTT HALSTEAD, E.. Enantioselective synthesis of (S)- and $(R)$ fluoxetine hydrochloride. Jornal Tetrahedron, v. 57, n. 50, p. 9925-9929, 2001.

ROSA, M. I. F. P. S. e SCHNETZLER, R. P. Sobre a importância do conceito transformação química no processo de aquisição do conhecimento químico. Química Nova na Escola, n. 8, p. 31-35, 1998.

SAINT CLAIR, E. A Construção Midiática da Depressão: Novos Personagens e Novas Tendências. XIV Congresso de Ciências da Comunicação do Sudeste. Sociedade Brasileira de Estudos Interdisciplinares de Comunicação, Anais... Rio de Janeiro: Intercom, p. R14-0483-1, 2009.

SANTOS, W. L. P. e SCHNETZLER, R. P. Educação em química: Compromisso com a cidadania. oㅡ ed. ljuí: Unijuí, 2003. 
SANTOS, W.; MORTIMER, E. A dimensão social do ensino de Química-um estudo exploratório da visão de professores. In: Encontro Nacional De Pesquisa Em Educação Em Ciências, 2, Valinhos. Anais... Porto Alegre: ABRAPEC, 1999. CD-ROM

TEIXEIRA, P. M. M. A Educação cientifica sob a Perspectiva da pedagogia Histórico- critica e do movimento CTS no ensino de ciências. Ciência \& Educação, Bauru. v. 9, n. 2, p. 177-190, 2003.

ZANON, L. B. Tendências Curriculares no Ensino de Ciências/Química: Um olhar para a contextualização e a interdisciplinaridade com princípios da formação escolar. In: ROSA, M. I P, ROSSI, A. V. Educação Química no Brasil: Memórias, Políticas e Tendências. Campinas - SP: Átomo, p. 235-262, 2008.

Danielle Silva Lima é licenciada em Química pela Universidade Federal de Goiás - Câmpus Jataí e professora da Secretaria da Educação do Estado de Goiás. danis_lima@hotmail.com Kathynne Carvalho Freitas é licenciada em Química pela Universidade Federal de Goiás - Câmpus Jataí. kathynne_carvalho@hotmail.com

Ricardo Alexandre Figueiredo Matos é bacharel em Química, Mestre e Doutor em Química Orgânica pela Universidade de Brasília (UnB). É professor Adjunto do Curso de Química da Universidade Federal de Goiás - Câmpus Jataí. coisodf@gmail.com

Márlon Herbert Flora Barbosa Soares é licenciado em Química pela Universidade Federal de Uberlândia. Mestre em Química e Doutor em Ciências (Química) pela Universidade Federal de São Carlos. É professor Associado no Instituto de Química da Universidade Federal de Goiás onde coordena o Laboratório de Educação Química e Atividades Lúdicas. www.lequal.com.br

Wesley Fernandes Vaz é licenciado em Química pela Universidade Estadual de Goiás. Mestre e Doutor em Química pela Universidade Federal de Goiás, com ênfase no Ensino de Química. É professor Adjunto do curso de Química da Universidade Federal de Goiás - Câmpus Jataí. wesleyfvaz@gmail.com 